\title{
A study of the approaches used to retrieve aerosol extinction, as applied to limb observations made by OSIRIS and SCIAMACHY
}

\author{
Landon A. Rieger ${ }^{1}$, Elizaveta P. Malinina ${ }^{2}$, Alexei V. Rozanov ${ }^{2}$, John P. Burrows ${ }^{2}$, Adam E. Bourassa ${ }^{1}$, and \\ Doug A. Degenstein ${ }^{1}$ \\ ${ }^{1}$ Institute of Space and Atmospheric Studies, University of Saskatchewan, Saskatoon, Canada \\ ${ }^{2}$ Institute of Environmental Physics, University of Bremen, Bremen, Germany
}

Correspondence: Landon A. Rieger (landon.rieger@usask.ca)

Received: 8 December 2017 - Discussion started: 2 January 2018

Revised: 12 April 2018 - Accepted: 2 May 2018 - Published: 15 June 2018

\begin{abstract}
Limb scatter instruments in the UV-vis spectral range have provided long-term global records of stratospheric aerosol extinction important for climate records and modelling. While comparisons with occultation instruments show generally good agreement, the source and magnitude of the biases arising from retrieval assumptions, approximations in the radiative transfer modelling and inversion techniques have not been thoroughly characterized. This paper explores the biases between SCIAMACHY v1.4, OSIRIS v5.07 and SAGE II v7.00 aerosol extinctions through a series of coincident comparisons as well as simulation and retrieval studies to investigate the cause and magnitude of the various systematic differences. The effect of a priori profiles, particle size assumptions, radiative transfer modelling, inversion techniques and the different satellite datasets are explored. It is found that the assumed a priori profile can have a large effect near the normalization point, as well as systematic influence at lower altitudes. The error due to particle size assumptions is relatively small when averaged over a range of scattering angles, but individual errors depend on the particular scattering angle, particle size and measurement vector definition. Differences due to radiative transfer modelling introduce differences between the retrieved products of less than $10 \%$ on average, but can introduce vertical structure. The combination of the different scenario simulations and the application of both algorithms to both datasets enable the origin of some of the systematic features such as high-altitude differences when compared to SAGE II to be explained.
\end{abstract}

\section{Introduction}

Stratospheric aerosols play an import role in several atmospheric processes, including radiative forcing and ozone depletion. For decades, monitoring of stratospheric aerosols from satellite observations was largely the domain of occultation instruments such as Stratospheric Aerosol and Gas Experiment (SAGE) II. However, since the 2000s aerosol extinction has been retrieved from limb scatter instruments such as the Optical Spectrograph and InfraRed Imaging System (OSIRIS) (Llewellyn et al., 2004; Bourassa et al., 2012, and references therein), the SCanning Imaging Absorption spectroMeter for Atmospheric CHartographY (SCIAMACHY) (Burrows et al., 1995; Bovensmann et al., 1999; von Savigny et al., 2015, and references therein) and the Ozone Mapping and Profile Suite Limb Profiler (OMPSLP) (Flynn et al., 2006; Loughman et al., 2018). While limb scatter provides greatly improved global coverage over occultation satellites, it requires additional assumptions and computationally expensive forward models to perform the inversions. Despite the difficulties, comparisons between limb scatter and occultation measurements generally agree favourably with mean biases in the $10-15 \%$ range during volcanically quiescent periods. While this is the average case, biases at certain latitudes and altitudes can be considerably larger. Additionally, biases after 2005 have not been well characterized due to the lack of baseline occultation measurements with which to compare.

This paper investigates the cause of the biases between the OSIRIS and SCIAMACHY aerosol extinction retrievals using comparisons with SAGE II and a series of simulation studies. The two limb-scattering instruments and the inver- 
sion techniques are described in Sect. 2. Also introduced here is the new version 1.4 SCIAMACHY aerosol extinction product used in this work. Initially, a triple comparison among OSIRIS, SCIAMACHY and SAGE II is performed in Sect. 3. As there was very little volcanic influence on the stratospheric aerosol load during the overlap period, this serves as a baseline for the agreement seen between the limb scatter and occultation aerosol records during volcanically quiescent times and motivates the investigation of error sources. Section 4 discusses the magnitudes of the errors that are expected from the assumptions in the OSIRIS and SCIAMACHY retrievals and radiative transfer models through a series of simulation studies. Section 5 applies the IUP and USask retrievals to both datasets to investigate differences due to the inversion techniques and radiance products. Lastly, conclusions and recommendations are discussed in Sect. 6

\section{The aerosol retrievals}

Generally, aerosol extinction retrievals for OSIRIS, SCIAMACHY and OMPS-LP limb-scattering instruments proceed in a similar fashion. First, radiance profiles at one or more wavelengths are used to construct a single measurement vector as a function of altitude. As this provides only one piece of information at each altitude, aerosol extinction is typically chosen as the retrieved quantity, although this is not the only possibility. However, extinction is the natural quantity retrieved from occultation instruments and allows for continuation of this historical record. Ideally, the measurement vector would be dependent only on the desired aerosol extinction parameter, but in practice it is also affected by the surface albedo, atmospheric density and aerosol optical properties including particle size, shape and composition. Typically, an effective Lambertian surface reflectivity is retrieved concurrently with the aerosol extinction, while the atmospheric density and optical properties are assumed using external information. Although atmospheric density is provided at high resolution by ECMWF (European Centre for Medium-Range Weather Forecasts) or MERRA, data on aerosol optical properties are much sparser and a notable limitation in the current retrievals.

Although particle size information has been retrieved from limb instruments in the past with OMPS-LP and OSIRIS (Rault and Loughman, 2013; Rieger et al., 2014) and more recently with SCIAMACHY (Malinina et al., 2018a), the standard operational products remain as extinction-only for the OSIRIS and OMPS-LP aerosol products. These extinction products have been used in numerous studies and continue to contribute to the stratospheric aerosol record (Kremser et al., 2016; Thomason et al., 2017), highlighting the importance of accurately characterizing not only precision but also biases in the current operational retrievals.

\subsection{OSIRIS v5.07}

OSIRIS was launched in 2001 aboard the Odin spacecraft (Llewellyn et al., 2004). The spectrograph produces limbscattered radiance profiles from 280 to $810 \mathrm{~nm}$, with typical sampling every $2 \mathrm{~km}$, a vertical resolution of $1 \mathrm{~km}$ and an altitude range from 7 to $75 \mathrm{~km}$. Odin is in a near-terminator orbit with an equatorial crossing time of approximately 06:00 on the descending node, providing limb measurements with a limited range of viewing geometries. Typically, solar scattering angles vary between 60 and $120^{\circ}$ with the largest values occurring in the tropics, and little correlation between the mean scattering angle and latitude. The OSIRIS measurements have been used in the inversions of multiple species with products now spanning over 15 years (McLinden et al., 2012). The inversions use the SASKTRAN radiative transfer model (Bourassa et al., 2008; Zawada et al., 2015) and a multiplicative algebraic reconstruction technique (MART) to retrieve ozone, $\mathrm{NO}_{2}$ and aerosol extinction at $750 \mathrm{~nm}$. This paper uses the OSIRIS v5.07 aerosol data product retrieved with the algorithm discussed in Bourassa et al. (2007, 2012), which simplifies to the Chahine inversion technique (Chahine, 1970) for the choice of tangent altitude weighting factors in the aerosol-specific portion of the MART retrieval. This algorithm will be referred to as the USask retrieval in this paper. For the radiative transfer modelling, a unimodal lognormal distribution is assumed with median radius, $r_{g}$ of $80 \mathrm{~nm}$ and distribution width, $\sigma_{g}$, of 1.6 as defined in Eq. (5). This distribution is consistent with mid-latitude optical particle counter (OPC) measurements during volcanically quiescent periods (Deshler et al., 2003), although the variability in the OPC measurements is large, as discussed in Sect. 4.3. Mie theory is used to calculate the aerosol scattering properties with a refractive index from Palmer and Williams (1975) assuming a $75 \%$ concentration of $\mathrm{H}_{2} \mathrm{SO}_{4}$ and $25 \% \mathrm{H}_{2} \mathrm{O}$. This produces a refractive index of $1.427+i 7.167 \times 10^{-8}$ at $750 \mathrm{~nm}$ and $1.432+i 0.0$ at $470 \mathrm{~nm}$. The USask measurement vector is defined as

$y_{j k}^{\prime}=\ln \left(\frac{I\left(\lambda_{k}, j\right)}{I\left(\lambda_{\text {ref }}, j\right)}\right)-\frac{1}{N} \sum_{j_{\mathrm{ref}}=m}^{m+N-1} \ln \left(\frac{I\left(\lambda_{k}, j_{\mathrm{ref}}\right)}{I\left(\lambda_{\mathrm{ref}}, j_{\mathrm{ref}}\right)}\right)$,

where the measurement vector, $y_{j k}^{\prime}$ at wavelength $k$ and altitude $j$ is the radiance, $I$, normalized by a reference altitude, $j_{\text {ref }}$, and shorter wavelength, $\lambda_{\text {ref }}$, that is generally less sensitive to aerosols. To reduce noise at the reference altitude $N$ measurements are used, beginning at tangent height $j_{\text {ref }}=m$. To improve the convergence speed of the relaxation technique (Barcilon, 1975; Chu, 1985), a modelled measurement vector assuming a molecular atmosphere is also used as a normalization, yielding the measurement vector

$y_{j k}=y_{j k}^{\prime}-y_{j k}^{\mathrm{mol}}$,

where $y^{\mathrm{mol}}$ is computed using Eq. (1), with the modelled radiances assuming an aerosol-free atmosphere. As this acts as 
a constant offset, it does not affect the sensitivity of the measurement vector to aerosols. However, in addition to improving convergence, this normalization also helps to identify the region of interest for the aerosol retrieval; after normalization by the molecular signal, the dominant components remaining are aerosol at lower altitudes and stray light at higher altitudes. The reference altitudes are chosen as the point, or points, where the measurement vector is at a minimum within the measurement noise, i.e. where both the stray light and aerosol signals are smallest. This produces a normalization that varies scan to scan, but typically produces reference altitudes between 25 and $40 \mathrm{~km}$ with lower altitudes near the poles. For the USask retrieval, $750 \mathrm{~nm}$ is used as the long wavelength, $\lambda_{k}$, and $470 \mathrm{~nm}$ is used as the reference, $\lambda_{\text {ref. At- }}$ mospheric data for pressure and temperature are interpolated to the OSIRIS scan location from the ECMWF operational analysis.

\subsection{SCIAMACHY v1.4}

SCIAMACHY (Burrows et al., 1995; Bovensmann et al., 1999) was a national contribution to the payload on ESA's Envisat Satellite, which was launched in March 2002. Envisat was placed in a sun-synchronous orbit at $800 \mathrm{~km}$ altitude with an equatorial crossing time of 10:00 on the descending node. In the limb mode the SCIAMACHY instrument scans across the flight direction with the total swath of $960 \mathrm{~km}$ and the centre of the scan displaced by a few degrees westwards from the flight direction. This results in solar scattering angles ranging from $30^{\circ}$ in the high northern latitudes to $150^{\circ}$ in the high southern latitudes with a strong latitudinal dependence. SCIAMACHY operation started in August 2002 and ended with a sudden loss of communication with the Envisat satellite in April 2012. SCIAMACHY performed measurements in eight spectral channels covering a wide spectral range from 214 to $2380 \mathrm{~nm}$ with a resolution varying from 0.2 to $1.5 \mathrm{~nm}$. During its mission, SCIAMACHY measured the solar radiation in nadir, limb scatter and solar-lunar occultation geometries and provided daily measurements of the solar spectral irradiance that have been used to retrieve a variety of species including aerosols, clouds, ozone, $\mathrm{BrO}$, $\mathrm{NO}_{2}$ and water vapour. For this study stratospheric aerosol retrievals are performed using the data from the limb scatter viewing geometry, where measurements are provided every $3.3 \mathrm{~km}$ with a vertical resolution of $2.6 \mathrm{~km}$ in the altitude range from approximately 0 to $100 \mathrm{~km}$.

The stratospheric aerosol extinction retrieval algorithm used in this study is an updated version of the algorithm described by von Savigny et al. (2015) and Ernst et al. (2012). The SCIAMACHY v1.4 retrievals, herein referred to as the IUP retrievals, use the newer version 8 SCIAMACHY Level 1 radiance data. Atmospheric pressure and temperature background profiles from ECMWF operational analysis data from the specific date, time and location of each SCIAMACHY limb measurement are used. In comparison to the previous version of the algorithm (von Savigny et al., 2015; Ernst et al., 2012) and the USask retrieval algorithm, the updated v1.4 algorithm drops the shorter, $470 \mathrm{~nm}$ wavelength normalization to reduce the uncertainties related to measurement noise and lower sensitivity to aerosols. The new measurement vector is given by

$y_{j k}=\ln \left(I\left(\lambda_{k}, j\right)\right)-\ln \left(I\left(\lambda_{k}, j_{\text {ref }}\right)\right)$.

To reduce noise on the measurements, all measured wavelengths within $\pm 2 \mathrm{~nm}$ of $\lambda_{k}$ are used in the retrieval. For the v1.4 extinction product the aerosol profiles are retrieved at $750 \mathrm{~nm}$. The retrieval uses measurements in the altitude range from around 12 to $35 \mathrm{~km}$ (depending on the latitude and season) with a reference tangent altitude of about $38 \mathrm{~km}$. The v1.4 aerosol extinction retrieval is performed on the measurement altitude grid, and the values below and above the retrieval range are fixed to the a priori. Effective Lambertian albedo of the underlying surface is concurrently retrieved based on the limb radiances near the reference tangent height to reduce the influence of clouds below the field of view, although clouds within the field of view remain an issue. To reduce their impact, extinction values greater than $0.001 \mathrm{~km}^{-1}$ are considered cloud contaminated and filtered after the retrieval is performed. To solve the inverse problem an iterative regularized inversion approach similar to that described by Rodgers (2000) is used. As in Ernst et al. (2012) it is assumed that the errors are uncorrelated, and the noise covariance matrix is chosen to be diagonal. The signal-to-noise ratio is set to 200 for all tangent heights. For the a priori covariance matrix the non-diagonal elements drop off exponentially with a correlation radius of $3.3 \mathrm{~km}$ and the diagonal elements correspond to a relative standard deviation (SD) of 1 .

Forward modelling, as well as retrievals, is done using the radiative transfer model with the retrieval code SCIATRAN3.7 (Rozanov et al., 2014). The scattering phase functions are calculated using Mie scattering theory, assuming spherical sulfate aerosol particles with a unimodal, lognormal size distribution. The refractive indices are calculated using the OPAC database (Hess et al., 1998). At $750 \mathrm{~nm}$ the real component of the index of refraction is 1.427 , and the imaginary component is $7.170 \times 10^{-8}$. The stratospheric aerosol parameters are defined from 12 to $46 \mathrm{~km}$, where it is assumed to consist of sulfuric droplets with $0 \%$ relative humidity in the surrounding atmosphere. The previous version 1.1 algorithm (von Savigny et al., 2015) used a lognormal particle size distribution with a median radius of $110 \mathrm{~nm}$ and width of 1.37 , also consistent with in situ observations by Deshler et al. (2003). Although there is no evidence to prefer either the particle size distribution used in the USask retrieval or that used by von Savigny et al. (2015), using different distributions complicates the comparison of limb-scattering retrievals, and so it is beneficial to make a consistent choice for this work. Therefore, the version 1.4 SCIAMACHY product uses the same lognormal assumption as the v5.07 OSIRIS 
product $\left(r_{g}=80 \mathrm{~nm}, \sigma_{g}=1.6\right)$. While a full validation of the version 1.4 is currently ongoing, initial comparisons with version 1.1 show smaller uncertainty of the individual retrievals, reduced profile oscillations and better parameterized upwelling radiation (resulting also in less sensitivity to underlying clouds) due to the retrieval of albedo.

\section{Coincident comparisons with SAGE II}

The SAGE II was launched in 1984 and operated until November 2005, providing one of the longest continuous records of stratospheric aerosols. As an occultation instrument, the SAGE II aerosol retrieval is insensitive to many of the assumptions required in the limb scatter retrievals, making for a robust, independent comparison. This work uses the version 7.00 SAGE II aerosol extinction data at 525 and $1020 \mathrm{~nm}$ (Damadeo et al., 2013). Several improvements have been made since version 6.2 that have resulted in aerosol extinction decreasing more quickly at higher altitudes. As both the OSIRIS and SCIAMACHY aerosol products are produced at $750 \mathrm{~nm}$, the SAGE II data are interpolated to this wavelength using the Ångström coefficient derived from the 525 and $1020 \mathrm{~nm}$ channels. Although this is not a perfect conversion, as the wavelength dependence is not strictly linear in log-wavelength log-extinction space, the error is generally limited to less than $10 \%$ for most particle sizes (Rieger et al., 2015). To test agreement between the three instruments a coincident comparison is performed when all instruments have collocated measurements. Measurements are used when OSIRIS and SCIAMACHY observations are within $\pm 5^{\circ}$ latitude, $\pm 20^{\circ}$ longitude and $\pm 24 \mathrm{~h}$ of the SAGE II tangent point. As limb measurements have approximately $200 \mathrm{~km}$ path lengths through the atmosphere, and scanning of a vertical profile typically occurs over a few degrees latitude, tightening these criteria does not generally improve agreement. To minimize the impact of clouds in the analysis extinction, values greater than $0.0025 \mathrm{~km}^{-1}$ have been excluded. Due to the relatively eruption-free period of this comparison, this has minimal effect on the comparisons removing approximately $3 \%$ of scans above $15 \mathrm{~km}$ and none above $20 \mathrm{~km}$. This criterion provides 2580 coincident measurements between 2002 and 2005, when all three instruments were operating. The comparison is broken into $20^{\circ}$ latitude bins to better distinguish biases related to latitude and solar geometry conditions. Results are shown in Fig. 1. In general, all instruments agree to within approximately $15 \%$ for most regions. Exceptions to this are at high altitudes and latitudes (such as panels a, b and $\mathrm{h}$ ) where both OSIRIS and SCIAMACHY retrieve lower values than SAGE II by up to $40 \%$ at $30 \mathrm{~km}$. At latitudes above $40^{\circ} \mathrm{N}$ SCIAMACHY shows systematically higher results than SAGE II for all altitudes below $30 \mathrm{~km}$. This effect increases with latitude up to approximately $40 \%$ at the highest northern latitudes and is visible in panels $g$ and $h$ of Fig. 1. Although the largest

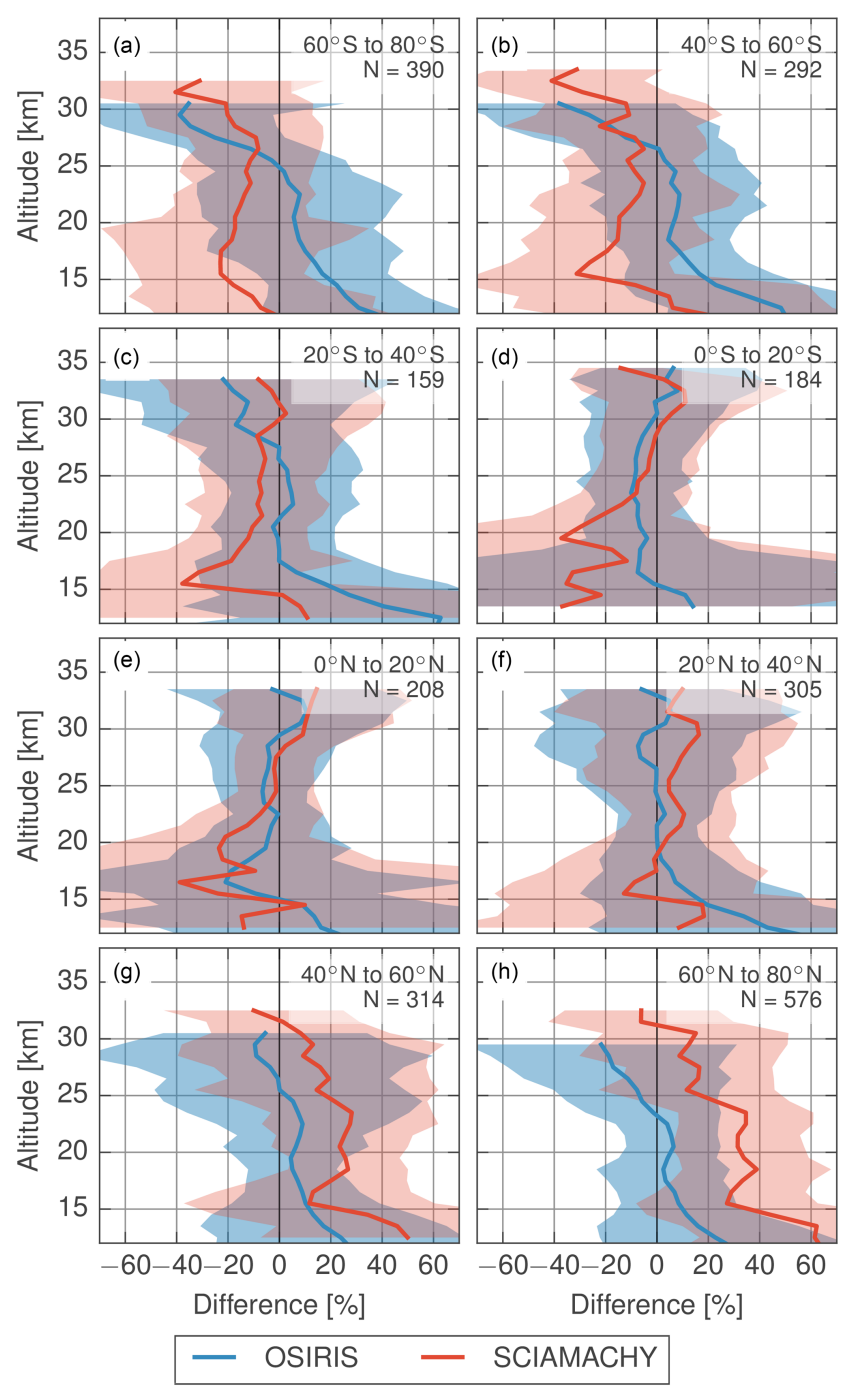

Figure 1. Coincident comparison between OSIRIS and SCIAMACHY measurements compared to SAGE II. Difference computed as (Instrument - SAGE II)/SAGE II $\times 100 \%$. Shaded regions indicated one SD of the differences from the median.

clouds have been removed, both limb scatter instruments are likely to still contain some cloud contamination near and below the tropopause and the differences compared to SAGE II show large SDs in these regions.

Several factors are expected to contribute to the differences between the aerosol extinction retrieved from the measurements of the occultation and limb scatter instruments, as well as the different biases between OSIRIS and SCIAMACHY. Limb scatter inversions use complex forward models which are not identical in their assumptions or approaches. The inversions themselves also differ in several ways, with SCIAMACHY using a regularized inversion technique and OSIRIS using MART. A priori assumptions, such as the choice of aerosol particle size distributions and extinction profiles, also affect the retrievals. The importance of 


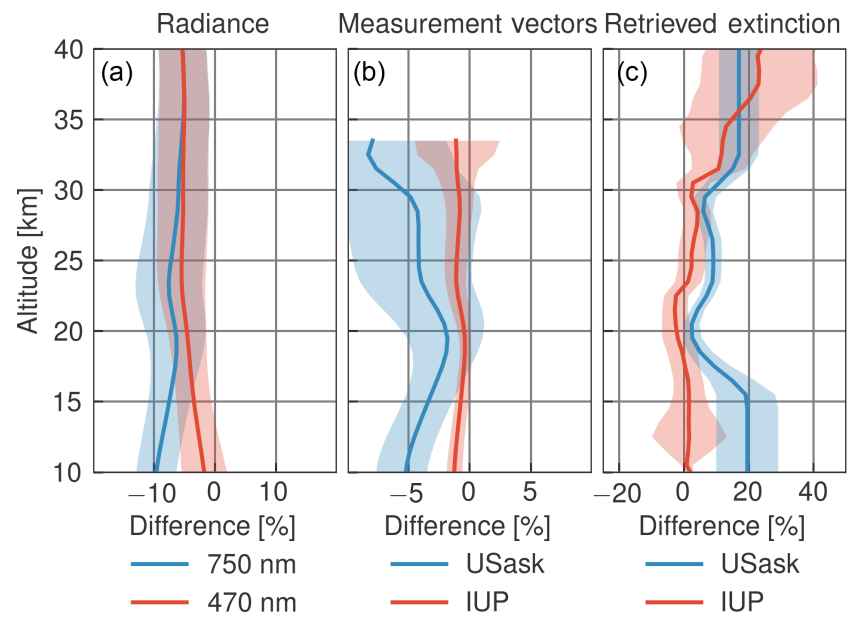

Figure 2. Comparisons of the radiative transfer models. Panel (a) shows the differences in radiance computed using SASKTRAN and SCIATRAN. Panel (b) shows the difference in measurement vectors. Panel (c) shows the difference in retrieved profiles. Differences in panels (a) and (b) are computed as (SASKTRAN-SCIATRAN)/ $($ SASKTRAN + SCIATRAN $) \times 200 \%$. Extinction error is computed as (retrieved - true $) /$ true $\times 100 \%$.

these effects depends on the viewing geometry of the instrument. OSIRIS and SCIAMACHY have significantly different viewing geometries as a result of the Envisat and Odin orbits. The following sections explore the significance of these different effects.

\section{Simulation study}

To test the sensitivity of the retrievals to assumed parameters and retrieval settings, a series of simulation studies is performed. The 2580 near-coincident scans from the SAGE II comparison are used as the test cases. These scans cover the full range of OSIRIS and SCIAMACHY geometries. While these scans are limited to pre-2006, the simulations use a range of atmospheric scenarios consistent with both background and volcanically perturbed conditions. Four factors are investigated in this study: the impact of different radiative transfer models, a priori extinction profile and particle size assumptions and choice of measurement vectors.

\subsection{Radiative transfer modelling}

It is difficult to decouple the retrieval algorithms from the radiative transfer models entirely due to differences in languages, input formats, and interfaces. However, differences between the IUP and USask retrievals due to the radiative transfer models can still be estimated by simulating measurements using one model and retrieving with the other. For this test, the SASKTRAN radiative transfer model is used to generate radiances that simulate the OSIRIS measurements.
These synthetic radiances are then used in the IUP retrieval which uses the SCIATRAN radiative transfer model. The same is then performed with the SCIATRAN simulated radiances and the USask retrieval using SASKTRAN, again on OSIRIS measurements. Although this is not a test of "correctness" of either model, nor a test of how well the radiative transfer models could agree, it provides an indication of the magnitude of differences that should be expected due to the configuration of the radiative transfer models as used in the retrievals. Figure 2 shows the differences in the modelled radiances and retrievals. Panel a shows the differences in the radiances at the 470 and $750 \mathrm{~nm}$ wavelengths. The radiances have systematic differences of approximately $5 \%$, with SCIATRAN producing larger radiance values than SASKTRAN. Some of this difference is due to model resolution settings. SASKTRAN simulations are performed at a higher vertical resolution of $1 \mathrm{~km}$, and when both models use this higherresolution vertical grid the agreement is improved to within $2-5 \%$. However, because the IUP retrieval is performed on a $3.3 \mathrm{~km}$ grid, the higher resolution is not required for SCIAMACHY retrievals. Although the variation in radiances between the models can occasionally reach $15 \%$, the normalizations used in the measurement vectors cancel much of the systematic differences. This can be seen in panel $b$, where differences in the measurement vectors, computed using the two different models, are shown. In this panel the red curve shows the percent difference between the IUP retrieval vectors defined in Eq. (3) when computed from SASKTRAN vs. SCIATRAN radiances. The blue curve shows the same, except computed using the USask measurement vector definition from Eq. (1). The high-altitude normalization used in the IUP retrieval decreases the differences between the models to less than $2 \%$ at most altitudes. If the short wavelength normalization is included the difference is larger, typically near $5 \%$, since the wavelength-dependent modelling differences vary more with altitude. How this difference translates to the retrieved extinction is shown in panel c. Here, the red curve shows the difference in the IUP retrieved extinction using SASKTRAN generated radiances compared to the true state. Similarly, the blue curve shows the same for USask retrieved extinction using SCIATRAN-generated radiances. The IUP retrieval produces errors in the retrieved extinction less than $5 \%$ for most of the aerosol layer, with a SD close to $5 \%$ as well. The larger differences in the USask measurement vector lead to larger differences in the USask the retrieved extinction, although errors are still typically less than $10 \%$. The exception to this is below $17 \mathrm{~km}$ and above $30 \mathrm{~km}$, where the sensitivity to aerosol is low, and therefore small changes in the radiative transfer cause large changes in the extinction. This highlights that the high-altitude normalization is effective not only in minimizing errors due to uncertainties in unknown physical quantities such as albedo but also in reducing errors due to model assumptions. Conversely, the short wavelength normalization has the potential to introduce additional 


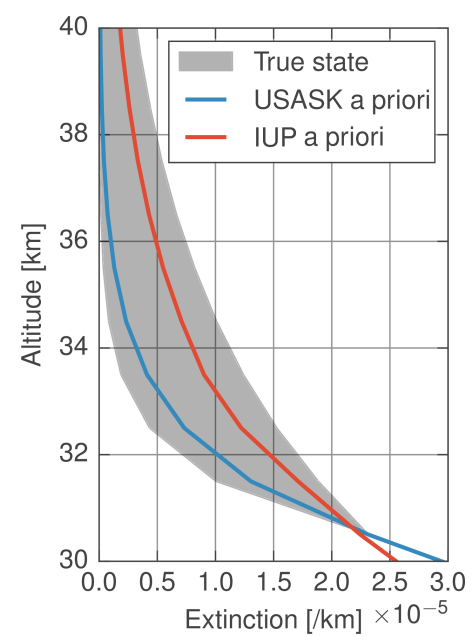

Figure 3. The range of the true state aerosol profiles is shown as the shaded region. The USask a priori is shown in blue and the IUP in red.

error if the radiative transfer model biases change with wavelength.

\subsection{A priori profiles}

The effect of the a priori profile on the retrieval is an important consideration and one that has the potential to vary substantially between retrieval methods. Although the MART relaxation used in the USask retrieval has no regularization, and the IUP retrieval is only weakly constrained by the a priori, the effect of the a priori at altitudes above the retrieval range can still play an important role. The aerosol here can couple to the lower altitudes due to the high-altitude normalization of the measurement vectors. While this normalization has many benefits, it has the drawback of coupling the error at high altitudes to all altitudes below. The USask retrieval scales the a priori above the retrieval range, at each iteration of the retrieval to match the top retrieved value and thus avoid sharp discontinuities in the retrieved profile. Therefore, the absolute error above the retrieval range depends on the shape of the a priori profile at and above the normalization and the retrieved aerosol just below the normalization. Conversely, the IUP extinction is fixed to the a priori value above the retrieval altitudes and so will depend less on the shape of the chosen a priori and more on the absolute value in the normalization range.

The effect of the a priori above the retrieval range is tested through a simulation study where the true high-altitude aerosol profile (i.e. the input profile used to generate the synthetic measurements) differs from that assumed in the retrievals. For this test an exponentially varying aerosol profile above $30 \mathrm{~km}$ is taken to be the truth. The slope of the exponential profile is then varied for each simulated OSIRIS and SCIAMACHY scan. The range of exponential profiles used as true states in the simulations is shown as the grey

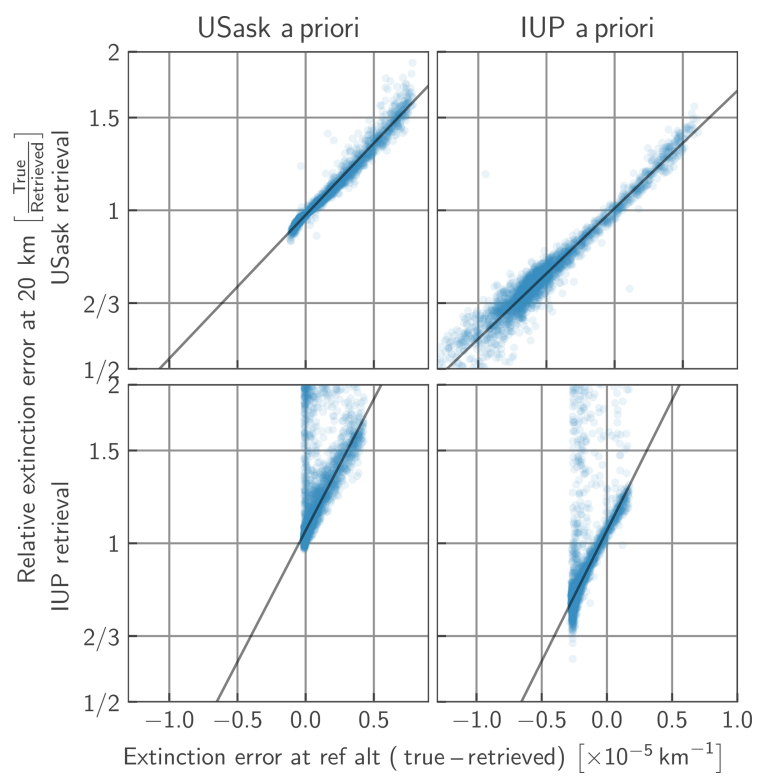

Figure 4. Relative error in the OSIRIS data retrievals at $20 \mathrm{~km}$ as a function of the absolute error in the true extinction at the reference point. The solid lines show the least squares fit to the data.

shaded region in Fig. 3. The USask and IUP a priori values are shown as the blue and red lines respectively. The shape of the a priori profile below $30 \mathrm{~km}$, as well as all other aerosol parameters such as particle size, is assumed correctly in the simulated retrievals to avoid introducing errors due to other retrieval parameters. The simulated data were then used to retrieve the extinction profile using the USask and IUP retrievals under two conditions. First, both retrievals are initialized with the USask a priori profile and, second, both are initialized with the IUP a priori profile.

Figure 4 shows the relationship between errors at the reference altitude to errors lower in the profile for four cases. The top row shows results for the USask retrieval with the bottom row showing the IUP retrievals. The left column shows results when the USask a priori profile is used for the retrievals, with the right column showing results when the larger IUP a priori is used. The solid line shows a linear best fit to the data. Generally, if aerosol is overestimated in the normalization range, due to an a priori profile that decays too slowly with altitude, the aerosol is overestimated for the entire retrieval. This is because the modelled vector is normalized by an overly large value, decreasing the magnitude in the retrieval range; as a result, extra aerosol is added to compensate. The error in the retrieved aerosol is very well correlated with the error in the normalization range, with little dependence on whether the USask or IUP retrieval is used. This holds well for all geometries tested and for both retrieval algorithms. However, higher altitudes are more sensitive to aerosol loading, and so show a larger error in the retrieved profile for a similar absolute error in the a priori as the normalization altitude is increased. This can be seen in the larger 


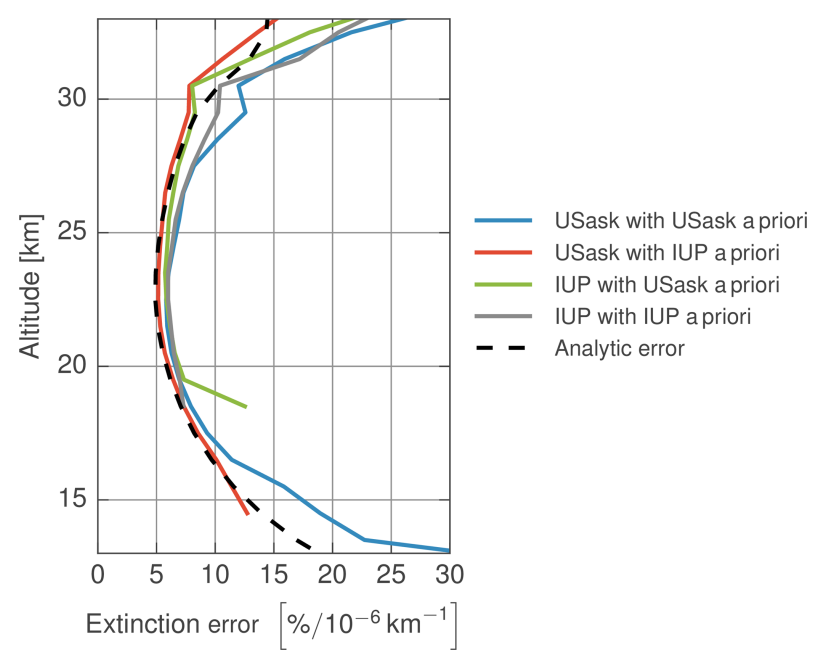

Figure 5. Percent error in the OSIRIS data retrievals as a function of altitude relative to an extinction error of $10^{-6} \mathrm{~km}^{-1}$ at $35 \mathrm{~km}$. Solid lines show values computed from the best fit line from the simulation studies shown in Fig. 4. Dashed line shows the error expected from the linear error analysis of Eq. (4).

sensitivity to a priori errors in the IUP retrieval, which uses a $38 \mathrm{~km}$ reference height, as opposed to the USask retrieval that used $35 \mathrm{~km}$. The same error of $10^{-6} \mathrm{~km}^{-1}$ at a normalization altitude of $38 \mathrm{~km}$ will cause approximately twice the error that it does at $35 \mathrm{~km}$. At low altitudes, less than approximately $14 \mathrm{~km}$, the sensitivity to aerosol is very low and the retrievals no longer show a clear relationship between the retrieval error and the a priori error.

The altitude dependence of the retrieved error, normalized by the error at $35 \mathrm{~km}$ is shown in Fig. 5 . We note that normalizing the IUP retrieval by the error at $35 \mathrm{~km}$ is not strictly correct as the reference altitude is at $38 \mathrm{~km}$. However, this allows for a consistent comparison between the two algorithms, and due to the relatively linear nature of the error it is not expected to introduce large biases. The retrieval error is smallest at around $22 \mathrm{~km}$, where the aerosol loading is highest, and the measurement sensitivity is still quite good, with error increasing above and below this altitude. The error can also be estimated without simulating the full retrieval using the equation

$\delta \mathbf{k}=\mathbf{G} \delta \mathbf{y}$,

where $\delta \mathbf{k}$ is the error in the retrieved extinction, $\mathbf{G}$ is the gain matrix or the sensitivity of the retrieved extinction to variations in $y$, and $\delta \mathbf{y}$ is the error in the measurement vector. In this case, $\delta \mathbf{y}$ is the error in the measurement vector due to errors in the assumed aerosol at the normalization altitude and above. As the retrieval error is quite linear with respect to errors in the high-altitude profile, $\delta \mathbf{y}$ in the retrieval range can be calculated directly from the Jacobian matrix, $\mathbf{K}$. This analysis as applied to the USask retrieval is plotted in Fig. 5 as the dashed line. Agreement between the analytic method and simulation study is excellent over the full range of values tested. As $\mathbf{G}$ and $\mathbf{K}$ are typically readily available from the inversion method, this can also be applied on an operational basis if estimates of the extinction error at the normalization point are known.

\subsection{Particle size}

In the standard extinction retrievals the aerosol optical properties are not retrieved and must therefore be assumed when retrieving extinction. Of primary importance in the IUP, USask and OMPS retrievals is the assumption of a fixed particle size. All three retrievals assume lognormal distributions that correspond to typical background conditions as measured by Deshler et al. (2003), albeit with somewhat different lognormal parameters. The lognormal distribution used in the retrievals is given by the equation

$n(r)=\frac{N}{\sqrt{2 \pi} \ln \left(\sigma_{g}\right) r} \exp \left(-\frac{\left(\ln \left(r_{g}\right)-\ln (r)\right)^{2}}{2 \ln ^{2}\left(\sigma_{g}\right)}\right)$,

where $r_{g}$ is the median radius, $\sigma_{g}$ the distribution width and $N$ the number density. During background conditions the median radius is generally larger than $40 \mathrm{~nm}$ but less than $200 \mathrm{~nm}$, depending on altitude. However, after volcanic eruptions, a second mode of particles with median radii up to a few microns may be present, further complicating the analysis. The effect of this constant unimodal particle size assumption was estimated to a degree by Rieger et al. (2015), but a limited number of geometries and cases were tested. More recently, Loughman et al. (2018) estimated the impact of particle size assumptions based on estimates of the phase function, but they did not fully propagate the error through the retrievals. This work extends these previous analyses to additional conditions and geometries and estimates the impact on the retrieved extinction.

To estimate errors due to particle size assumptions two sets of simulations are performed. First, a study to estimate errors in the retrieved extinctions during relatively quiescent periods is done, when only a fine mode of aerosols is present. For these simulations, the fine-mode lognormal parameter profiles as measured by the OPC in Wyoming by Deshler et al. (2003) between 2001 and 2014 are used as inputs for the simulated data. This provides 44 unique particle size profiles. To avoid noise and high-frequency oscillations the OPC profiles are smoothed to a vertical resolution of approximately $3 \mathrm{~km}$. The extinction profile was set to twice that of the a priori assumption, with no change in the shape to avoid including a priori errors in this portion of the study. The second set of simulations covers conditions more representative of those after volcanic eruptions, when an additional mode of larger particles is present. For this case, the smoothed coarse mode as measured by the OPC is also added to the true extinction profile. The number densities of the fine and coarse modes are set such that the coarse mode accounts for $70 \%$ of 

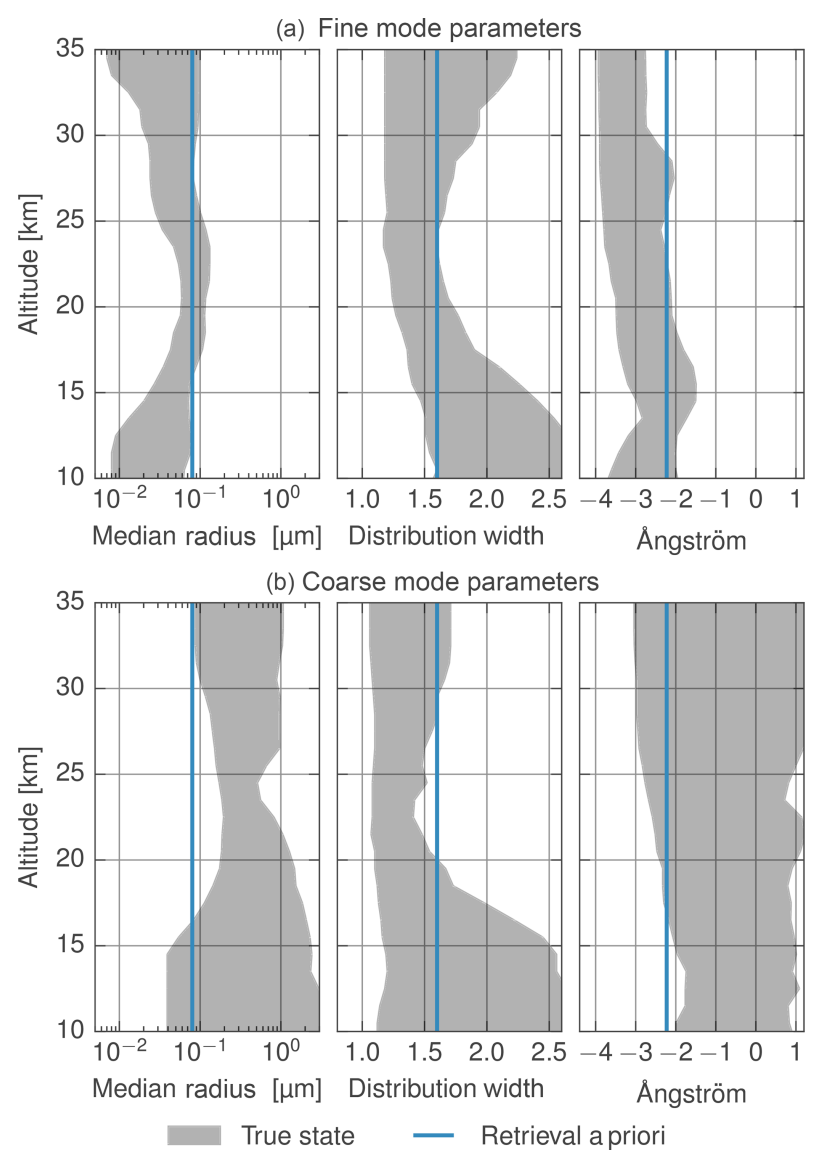

Figure 6. The range of particle sizes tested as a function of altitude. Panel (a) shows the fine-mode parameters and panel (b) the coarse mode. The blue lines show the USask and IUP a priori values assumed in the retrievals. The grey shaded region shows the range of values used in the simulations.

the total extinction. In each case, the coincident OSIRIS and SCIAMACHY scans were simulated using a random OPC particle size profile and a random albedo between zero and one as the true state. Figure 6 shows the range of median radii, widths and Ångström exponents (calculated between 525 and $750 \mathrm{~nm}$ ) used in the simulations, as well as the a priori values.

The standard USask algorithm was then used to retrieve extinction with the simulated data. These retrievals were also repeated using the USask algorithm but without the short wavelength normalization to determine its effect. The top row of Fig. 7 shows the relative error in the retrieved extinction for the standard USask retrieval when only a fine mode of particles is present, grouped by scattering angle. The colour of the line indicates the Angström coefficient. Only the SCIAMACHY geometries are shown here, as the OSIRIS results are very similar, but with a reduced range of scattering angles. Generally, errors are largest in the strongly forward and backscattering cases, with a strong dependence on the Ångström coefficient. The assumed size distribution has an Ångström coefficient of 2.3, and consequently when the true state is near this value the retrieval has little error. At altitudes above $25 \mathrm{~km}$, however, this assumption is consistently too high and leads to large errors, particularly in strongly forward scattering conditions.

The second row of Fig. 7 shows the same, but when the retrieval does not use a short wavelength normalization. In this case, the error is reduced in forward scattering conditions but increased in backscatter, particularly at lower altitudes, where sensitivity to aerosol is poor. The third row shows retrievals when the true state includes a second coarse mode of particles. In this case the assumption of an Ångström coefficient of 2.3 is generally more accurate at higher altitudes, and so the error above $20 \mathrm{~km}$ is reduced compared to the finemode-only case. However, the dependence on Ångström coefficient is weaker for the bimodal distributions, with many different particle sizes producing comparable errors. The effect of normalization is also not as clear under these more volcanic conditions, with only strongly forward scattering geometries showing a clear preference for no wavelength normalization.

This dependence on Ångström coefficient and scattering can be seen more clearly in Fig. 8, which shows a cross section of the results in Fig. 7 at $20 \mathrm{~km}$, as well as the results from OSIRIS geometries. Each panel shows the relative error in the retrieved extinction as a function of the true Angström coefficient at $20 \mathrm{~km}$. The colour of each point indicates the scattering angle of the measurement. Panels $a$ and $b$ show results for the fine-mode-only simulations, while $\mathrm{c}$ and $\mathrm{d}$ show results from bimodal cases. Panels a and c shows results from OSIRIS geometries, and those from SCIAMACHY geometries are presented in panels $b$ and $d$. The retrievals without the short wavelength normalization are shown in the right four panels. If only fine-mode particles are included in the simulated atmosphere, the error in the retrieval can be well parameterized by the Ångström coefficient and the solar scattering angle of the measurement. When the Ångström coefficient is assumed correctly the error in the retrieval is less than $10 \%$, nearly independent of the particular lognormal parameters. As the error in the Ångström coefficient increases, so does the error in the retrieval, up to $100 \%$ for OSIRIS geometries. For SCIAMACHY geometries the range of scattering angles and errors can be larger due to larger variations in the aerosol phase function at extremely large and small angles. With a short wavelength normalization the retrievals show errors that are mostly symmetric around zero. While this will help to reduce biases over longer periods of time when a large range of scattering angles are sampled, seasonal biases are still to be expected as different scattering angles are sampled over the course of a year. Similarly, latitudinal biases are likely in the SCIAMACHY data as scattering angle depends strongly on latitude. Without a short wavelength normalization the general spread and shape of the errors is similar; however, the errors are not centred around zero with aerosol being overestimated more often than not. In this case, 


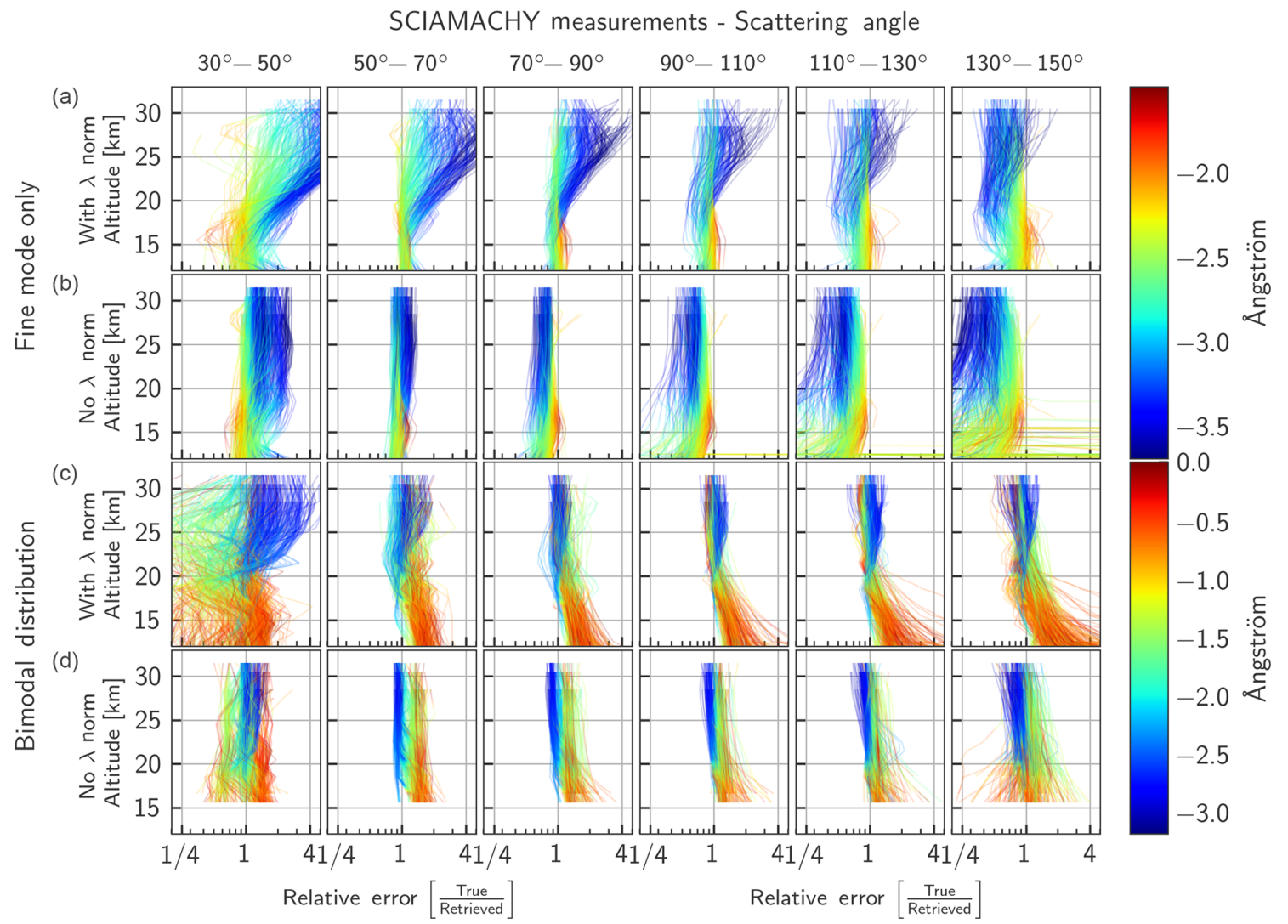

Figure 7. Error in the retrieved USask extinction for the simulated SCIAMACHY measurements grouped by the scattering angle for four different cases. The top two rows show results when only a fine mode of aerosols are present; the bottom two rows have both a fine and coarse mode. In both cases retrievals are done with a short wavelength normalization (a and $\mathbf{c})$ and without (b and $\mathbf{d})$. The colour of the lines indicates the Ångström coefficient.
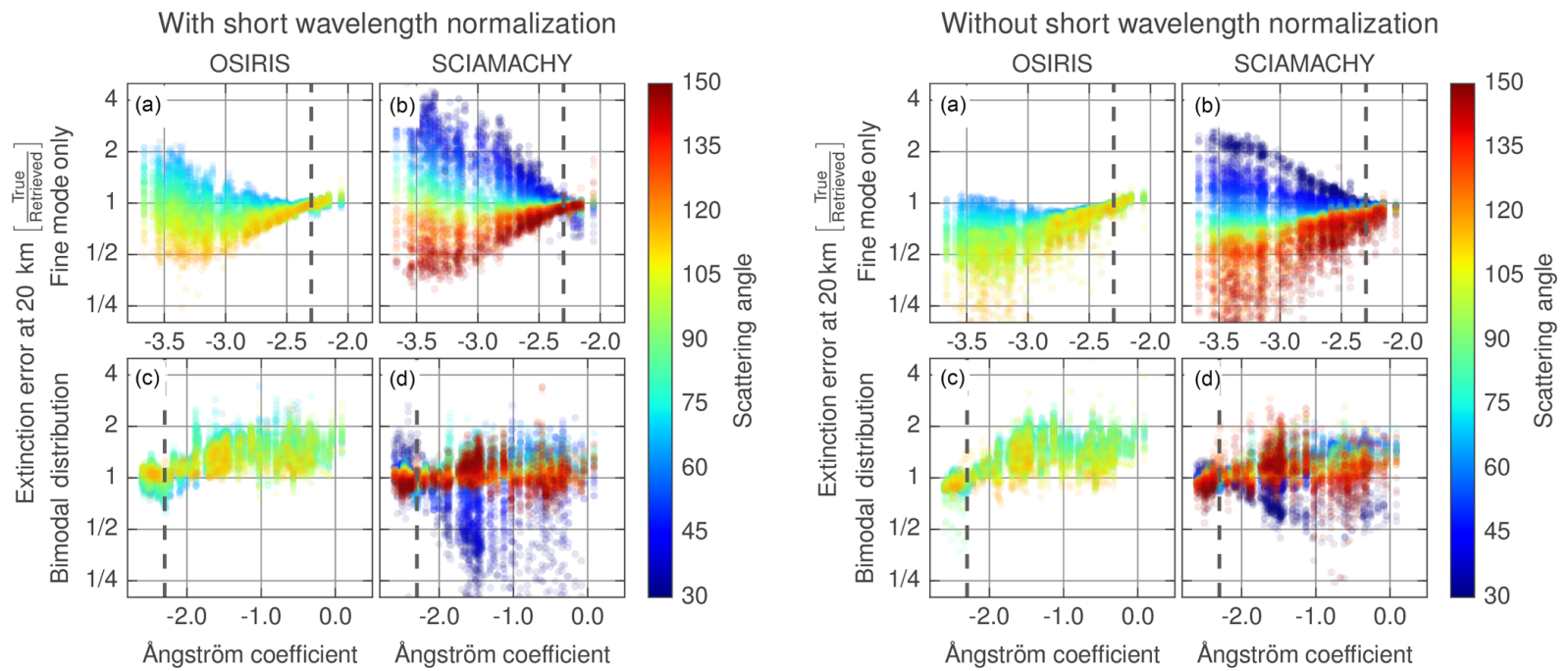

Figure 8. Error in the retrieved USask extinction as a function of Ångström coefficient at $20 \mathrm{~km}$. The colour of the points shows the solar scattering angle. The top row shows the error for conditions when only a fine mode of aerosol is present. The bottom row shows the error when there is both a fine- and coarse-mode distribution. The black dashed line indicates the Ångström coefficient corresponding to the particle size distribution used in the retrievals. 
the error is minimized during forward scattering conditions when scattering angles are near $60^{\circ}$. When short wavelength normalization is used the error is at a minimum near $90^{\circ}$; subsequently the error for forward scatting geometries is increased, while it is decreased for backscattering geometries.

When coarse-mode particles are included, the phase functions can vary more widely for a given Ångström coefficient, leading to less of a clear relationship in the retrieved error. This can be seen in panels c and d of Fig. 8, where much weaker correlation between the Ångström coefficient, solar scattering angle and extinction error is visible. Even when the Ångström coefficient is assumed correctly, differences in the lognormal parameters can induce errors of $30 \%$ in the retrieval for OSIRIS geometries and $50 \%$ for SCIAMACHY geometries. While the error is less correlated, errors are not systematically larger than during volcanically quiescent periods, but do have a tendency to introduce low biases in the retrieved results for most geometries and particle sizes. Additionally, while backscatter can still have large biases, they are not as large at the extreme scattering angles as during fine-mode-only conditions. During bimodal conditions the error in both the normalized and non-normalized retrievals is comparable, except during strongly forward scattering conditions when the short wavelength normalization increases the error. In general, this shows that the short wavelength normalization is beneficial during background periods under backscattering conditions, but generally increases the error during forward scatter. Additionally, in forward scatter both the 470 and $750 \mathrm{~nm}$ wavelengths are positively sensitive to aerosol, so the wavelength ratio will tend to decrease the sensitivity to aerosol and decrease the retrieved precision due to measurement noise as well.

\section{Retrieval study}

In Sect. 4 the sensitivity to retrieval assumptions and radiative transfer modelling was estimated. In this section, we explore the applicability of the USask retrieval to the SCIAMACHY measurements and vice versa, both to confirm the simulation studies and to better understand the sensitivity of the retrievals to differences in the radiance products. The same set of coincident SAGE II scans is used for this study, with comparisons performed in the same way as those presented in Sect. 3.

Figure 9 shows the USask retrieval applied to both instruments. Retrievals using the SCIAMACHY measurements agree very well with those using OSIRIS and show many of the same biases with respect to SAGE II. Both instruments show underestimation with respect to SAGE II at high altitudes and latitudes. If this was due to inaccuracies in the assumed particle size the error would be expected to change signs between hemispheres as the SCIAMACHY solar scattering angle goes from backscattering to forward scattering, which is not the case. Instead, these high-altitude errors are
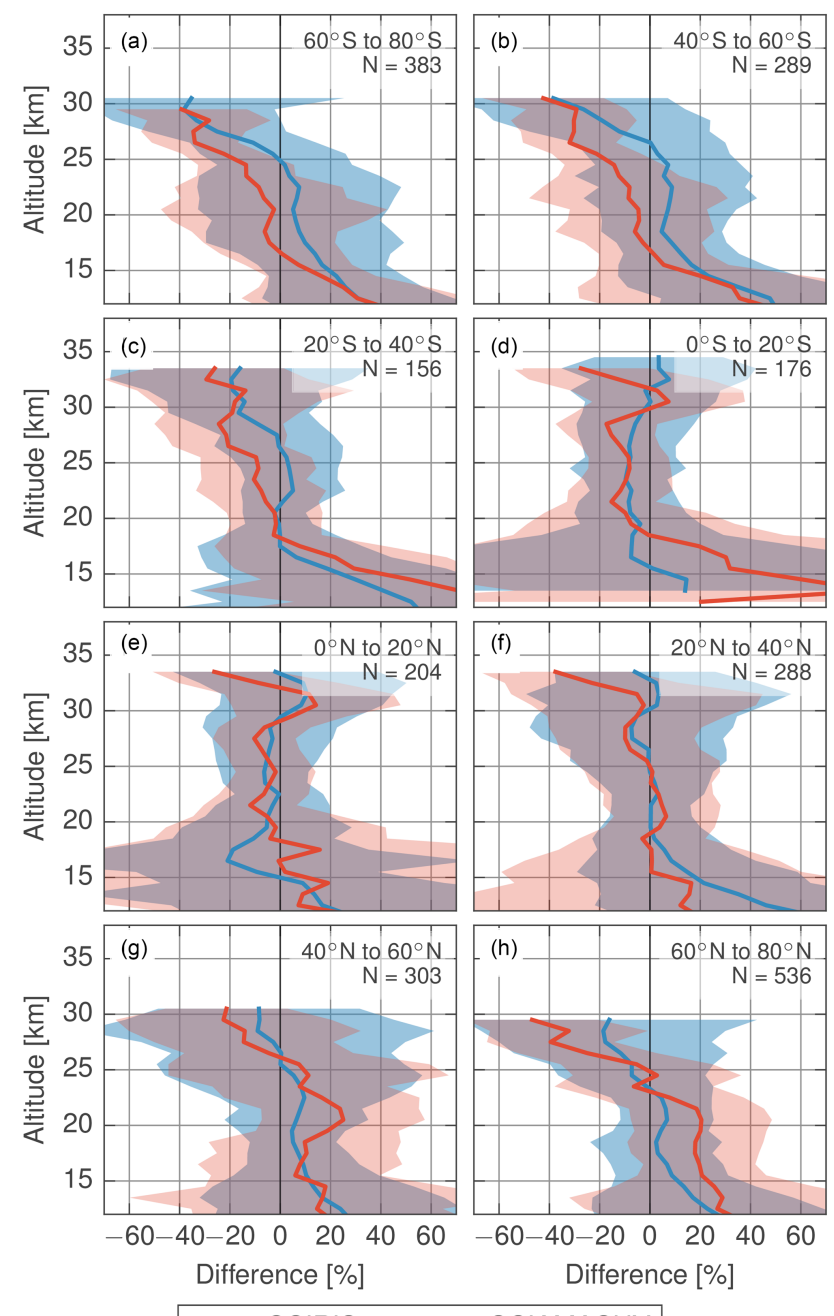

- OSIRIS

Difference [\%]

SCIAMACHY

Figure 9. Coincident comparison with SAGE II when both OSIRIS and SCIAMACHY measurements have been processed with the USask algorithm.

more likely to be caused by errors in the assumed a priori extinction profile at high altitudes where the measurements are normalized, as the effect of this is nearly independent of solar geometry. From Fig. 5 errors of $3 \times 10^{-6} \mathrm{~km}^{-1}$ in the reference altitude range could explain biases of $-30 \%$ at high altitudes. Additionally, both instruments have some stray light at these higher altitudes that increases the radiance signal. This changes the shape of the aerosol measurement vector and is likely a contributing factor to the low biases at high altitudes and latitudes. Unfortunately, both a priori and stray light errors have similar systematic biases on the profile making them difficult to separate except in simulation, and errors in the a priori can either help to cancel or exacerbate errors due to stray light. The shift in the SCIAMACHY measurements from low biases in the Southern Hemisphere to high biases in the Northern Hemisphere is present, as was seen in 

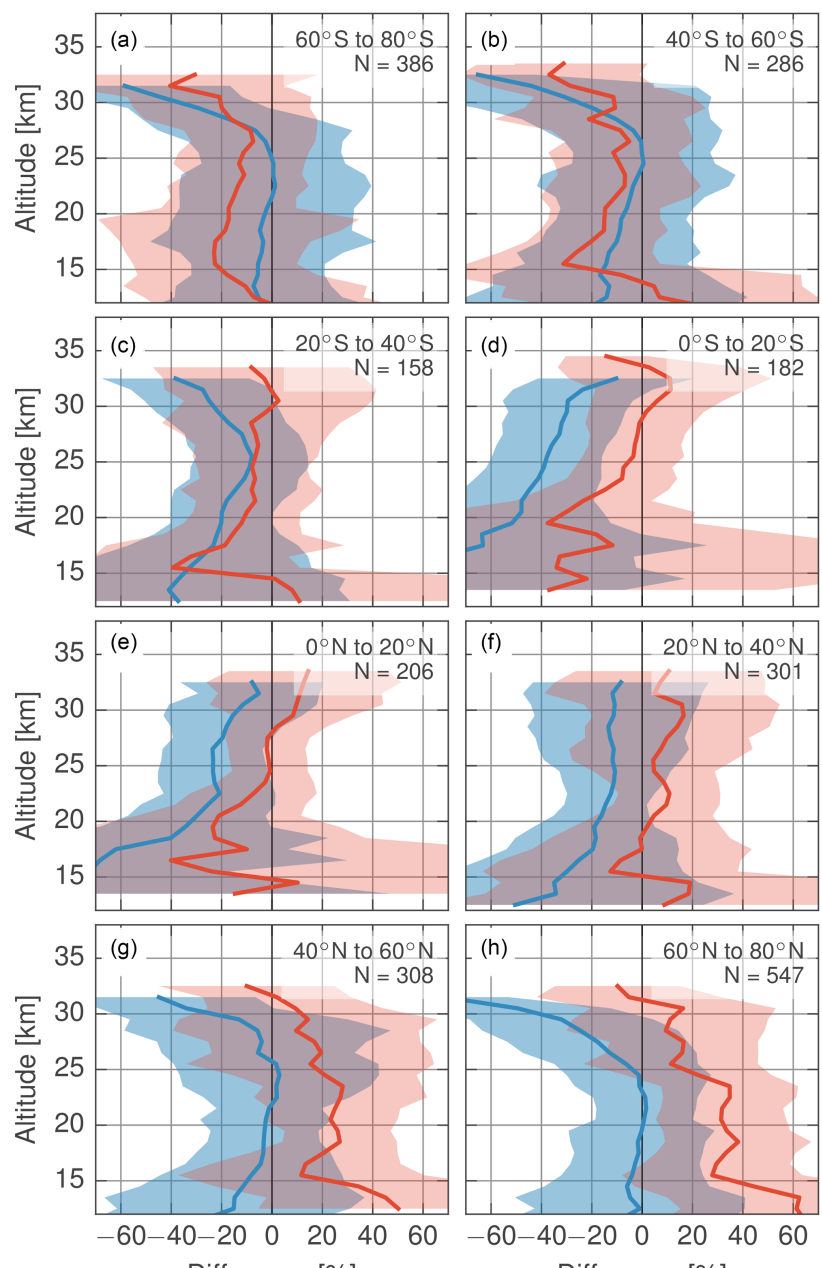

Difference [\%]

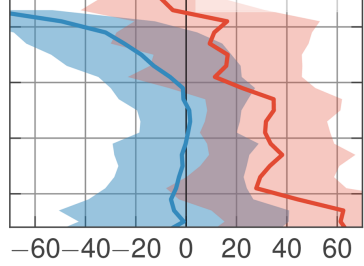

- OSIRIS - SCIAMACHY

Figure 10. Coincident comparison with SAGE II when both OSIRIS and SCIAMACHY measurements have been processed with the IUP algorithm.

the IUP retrieval in Fig. 1, again suggesting a particle size error. In the USask retrieval this shift is approximately 20 $30 \%$ between hemispheres, which from Fig. 8 would be consistent with an overestimation of the Ångström coefficient by approximately 0.3 , i.e. an assumption that particles are too large at the high latitudes.

The IUP retrieval applied to both the SCIAMACHY and OSIRIS data is shown in Fig. 10. OSIRIS solar scattering angles do not vary as strongly between the northern and southern hemispheres, and so the OSIRIS retrievals do not exhibit the same shift from low biases in the south to high biases in the north that are seen in the SCIAMACHY measurements. The impact of the a priori choice can also be seen here. For the OSIRIS retrievals the USask a priori was used without scaling, resulting in low aerosol values in the normalization range and leading to lower aerosol values at all altitudes.
However, if the IUP a priori is used the retrievals are substantially higher when compared to SAGE II (not shown). This is consistent with the results from Sect. 4.2, in that larger a priori values in the normalization range lead to larger values at all altitudes.

This highlights the sensitivity to the chosen a priori and reference altitudes and the limitations of both the USask and IUP approaches. The USask technique of scaling an a priori profile that decays rapidly with altitude works with both instruments provided the normalization altitude is chosen to minimize stray light. The variable normalization altitude ensures there is sufficient aerosol signal to determine the scaling, while the quickly decaying profile ensures the measurement vector is only weakly dependent on the scaling applied. However, while this provides a relatively robust retrieval it is likely to cause the aerosol to be underestimated at the normalization point, leading to low biases in the retrieved extinction, particularly at high altitudes. Conversely, the larger fixed a priori used in the IUP retrieval works well for SCIAMACHY when an appropriate reference altitude is chosen and can reduce biases at high altitudes. However, it yields poor results when applied to the OSIRIS measurements, illustrating the necessity of properly matching the normalization altitudes with the stray light characteristics and choice of a priori when using a fixed a priori profile. Together, the stray light, choice of normalization altitudes and a priori profile in the normalization range have a complex interplay. This can be seen panels $\mathrm{a}, \mathrm{b}, \mathrm{g}$ and $\mathrm{h}$, where the OSIRIS biases at low altitudes are reduced compared to the USask retrieval (Fig. 9), despite not improving the retrievals at high altitudes. Conversely, the biases are increased elsewhere (panels c-f). Unfortunately, without more detailed knowledge of the stray light and error in the extinction in the normalization altitudes, the relative contribution of each cannot be determined.

\section{Conclusions}

The updated SCIAMACHY v1.4 aerosol extinction product shows good agreement with coincident SAGE II measurements, typically within $20 \%$ for most regions. Exceptions to this include high northern latitudes where larger positive biases of $20-40 \%$ are present and altitudes above $25 \mathrm{~km}$ in the southern high latitudes where negative biases are present. The differences between the limb and occultation measurements are well explained by two primary causes. First, the choice of a priori profiles is important in the limb retrieval due to the high-altitude normalization. If the shape of the a priori profile is assumed incorrectly in the USask retrieval the scaling applied to the profile in the retrievals will produce incorrect aerosol in the reference altitude, resulting in biases at all altitudes. The IUP retrieval fixes the aerosol profile above the retrieval range to the a priori value and errors couple similarly to lower altitudes. For both retrievals extinction errors in the reference altitude of $10^{-6} \mathrm{~km}^{-1}$ lead to er- 
rors in the retrieved extinction of $5 \%$ near the aerosol peak and up to $20 \%$ just below the reference altitude. Second, incorrect particle size generally shows a small mean difference when averaged over a range of scattering angles, but can have large differences of $100 \%$ or more for individual cases, particularly for strongly forward and backscattering viewing conditions. This is especially important for orbits that systematically sample solar scattering conditions as a function of latitude. Simulations including a coarse mode of particles suggest a low bias in the retrieved extinctions during volcanically perturbed periods is likely for most geometries. However, the magnitude of the error is not expected to be systematically larger than the during background conditions on a profile-by-profile basis. Additionally, while the USask and IUP retrievals use the same particle size assumptions, the biases are different for both the instruments and retrieval algorithms due to the difference in viewing geometries and definition of the measurement vectors. The error due to particle size can be reduced in backscatter geometries through the short wavelength normalization. However, this normalization has the opposite effect in strongly forward scattering conditions, where it makes the retrievals more sensitive to particle size assumptions and measurement noise. Differences in SASKTRAN and SCIATRAN radiative transfer models can cause systematic differences of up to $10 \%$ between the retrieved products and may explain some of the vertical structure in the comparisons, but they are not expected to be a primary driver of the differences.

Future retrievals would benefit from improved a priori estimates of the aerosol extinction above $30 \mathrm{~km}$ and particle size distributions. In particular, OSIRIS retrievals could benefit from larger assumed a priori values at higher latitudes to reduce low biases compared to SAGE II. SCIAMACHY retrievals would benefit most from improved particle size estimates to reduce north-south biases. However, if this information remains limited, careful use of wavelength normalization (and the lack thereof) for specific viewing geometries has the potential to reduce retrieval biases. Additionally, although the USask and IUP approaches to aerosol in the normalization range of the measurements are different (scaling vs. fixed to a priori respectively), both show comparable errors in the retrieved product for a given error in the normalization range. Robust measurements of high-altitude aerosol are therefore needed to establish whether a fixed a priori or a scaled one leads to less error at these altitudes. In summary, this study investigates the retrieval of extinction from the limb viewing observations of scattered solar radiance by the satellite borne instruments OSIRIS and SCIAMACHY. It provides a detailed analysis of our understanding of the systematic errors associated with these data products and biases with respect to the SAGE II measurements of extinction.

Code and data availability. The OSIRIS data can be downloaded from ftp://odin-osiris.usask.ca, after contacting the authors for reg- istration. The SCIAMACHY dataset can be downloaded at http: //www.iup.uni-bremen.de/scia-arc/ (Malinina et al., 2018b). SAGE data were obtained from the NASA Langley Research Center EOSDIS Distributed Active Archive Center. Information on downloading and using the SASKTRAN radiative transfer model can be found at https://arg.usask.ca/docs/sasktran/ (Zawada et al., 2018) and the SCIATRAN code and documentation is available at http: //www.iup.uni-bremen.de/sciatran/ (Rozanov, 2018).

Competing interests. The authors declare that they have no conflict of interest.

Acknowledgements. This work was supported by the Natural Sciences and Engineering Research Council (Canada), the Canadian Space Agency, European Space Agency (ESA) through the SQWG and SPIN projects, the German Aerospace Center (DLR) through the SADOS project, the German Federal Ministry of Education and Research (BMBF) through the ROMIC project, the University and State of Bremen and the German Academic Exchange Service (DAAD), which provided a grant for Landon Rieger to visit the University of Bremen. Odin is a Swedish-led satellite project funded jointly by Sweden (SNSB), Canada (CSA), France (CNES), and Finland (Tekes).

Edited by: Omar Torres

Reviewed by: three anonymous referees

\section{References}

Barcilon, T. V.: On Chahine's relaxation method for the radiative transfer equation, J. Atmos. Sci., 32, 1626-1630, 1975.

Bourassa, A., Degenstein, D., Gattinger, R., and Llewellyn, E.: Stratospheric aerosol retrieval with optical spectrograph and infrared imaging system limb scatter measurements, J. Geophys. Res.-Atmos., 112, D102017, https://doi.org/10.1029/2006JD008079, 2007.

Bourassa, A., Degenstein, D., and Llewellyn, E.: SASKTRAN: a spherical geometry radiative transfer code for efficient estimation of limb scattered sunlight, J. Quant. Spectrosc. Ra., 109, 5273, 2008.

Bourassa, A. E., Rieger, L. A., Lloyd, N. D., and Degenstein, D. A.: Odin-OSIRIS stratospheric aerosol data product and SAGE III intercomparison, Atmos. Chem. Phys., 12, 605-614, https://doi.org/10.5194/acp-12-605-2012, 2012.

Bovensmann, H., Burrows, J., Buchwitz, M., Frerick, J., Noël, S., Rozanov, V., Chance, K., and Goede, A.: SCIAMACHY: mission objectives and measurement modes, J. Atmos. Sci., 56, 127-150, 1999.

Burrows, J., Hölzle, E., Goede, A., Visser, H., and Fricke, W.: SCIAMACHY - scanning imaging absorption spectrometer for atmospheric chartography, Acta Astronaut., 35, 445-451, 1995.

Chahine, M. T.: Inverse problems in radiative transfer: determination of atmospheric parameters, J. Atmos. Sci., 27, 960-967, 1970. 
Chu, W. P.: Convergence of Chahine's nonlinear relaxation inversion method used for limb viewing remote sensing, Appl. Optics, 24, 445-447, 1985.

Damadeo, R. P., Zawodny, J. M., Thomason, L. W., and Iyer, N.: SAGE version 7.0 algorithm: application to SAGE II, Atmos. Meas. Tech., 6, 3539-3561, https://doi.org/10.5194/amt-6-35392013, 2013.

Deshler, T., Hervig, M., Hofmann, D., Rosen, J., and Liley, J.: Thirty years of in situ stratospheric aerosol size distribution measurements from Laramie, Wyoming $\left(41^{\circ} \mathrm{N}\right)$, using balloon-borne instruments, J. Geophys. Res.-Atmos., 108, 4167, https://doi.org/10.1029/2002JD002514, 2003.

Ernst, F., von Savigny, C., Rozanov, A., Rozanov, V., Eichmann, K.U., Brinkhoff, L. A., Bovensmann, H., and Burrows, J. P.: Global stratospheric aerosol extinction profile retrievals from SCIAMACHY limb-scatter observations, Atmos. Meas. Tech. Discuss., 5, 5993-6035, https://doi.org/10.5194/amtd-5-5993-2012, 2012.

Flynn, L. E., Seftor, C. J., Larsen, J. C., and Xu, P.: The ozone mapping and profiler suite, in: Earth Science Satellite Remote Sensing, Springer, 279-296, 2006.

Hess, M., Koepke, P., and Schult, I.: Optical properties of aerosols and clouds: The software package OPAC, B. Am. Meteorol. Soc., 79, 831-844, 1998.

Kremser, S., Thomason, L. W., von Hobe, M., Hermann, M., Deshler, T., Timmreck, C., Toohey, M., Stenke, A., Schwarz, J. P., Weigel, R., Fueglistaler, S., Prata, F. J., Vernier, J.-P., Schlager, H., Barnes, J. E., Antuña-Marrero, J.-C., Fairlie, D., Palm, M., Mahieu, E., Notholt, J., Rex, M., Bingen, C., Vanhellemont, F., Bourassa, A. E., Plane, J. M. C., Klocke, D., Carn, S. A., Clarisse, L. Trickl, T., Neely, R., James, A. D. Rieger, L., C. Wilson, J. C., and Meland, B.: Stratospheric aerosol - observations, processes, and impact on climate, Rev. Geophys., 54, 278-335, https://doi.org/10.1002/2015RG000511, 2016.

Llewellyn, E. J., Lloyd, N. D., Degenstein, D. A., Gattinger, R. L., Petelina, S. V., Bourassa, A. E., Wiensz, J. T., Ivanov, E. V., McDade, I. C., Solheim, B. H., McConnell, J. C., Haley, C. S., von Savigny, C., Sioris, C. E., McLinden, C. A., Griffioen, E., Kaminski, J., Evans, W. F. J., Puckrin, E., Strong, K., Wehrle, V., Hum, R. H., Kendall, D. J. W., Matsushita, J., Murtagh, D. P., Brohede, S., Stegman, J., Witt, G., Barnes, G., Payne, W. F., Piché, L., Smith, K., Warshaw, G., Deslauniers, D. L., Marchand, P., Richardson, E. H., King, R. A., Wevers, I., McCreath, W., Kyrölä, E., Oikarinen, L., Leppelmeier, G. W., Auvinen, H., Mégie, G., Hauchecorne, A., Lefèvre, F., de La Nöe, J., Ricaud, P., Frisk, U., Sjoberg, F., von Schéele, F., and Nordh, L.: The OSIRIS instrument on the Odin spacecraft, Can. J. Phys., 82, 411-422, 2004.

Loughman, R., Bhartia, P. K., Chen, Z., Xu, P., Nyaku, E., and Taha, G.: The Ozone Mapping and Profiler Suite (OMPS) Limb Profiler (LP) Version 1 aerosol extinction retrieval algorithm: theoretical basis, Atmos. Meas. Tech., 11, 2633-2651, https://doi.org/10.5194/amt-11-2633-2018, 2018.

Malinina, E., Rozanov, A., Rozanov, V., Liebing, P., Bovensmann, H., and Burrows, J. P.: Aerosol particle size distribution in the stratosphere retrieved from SCIAMACHY limb measurements, Atmos. Meas. Tech., 11, 2085-2100, https://doi.org/10.5194/amt-11-2085-2018, 2018a.
Malinina, E., Rozanov, A., Vountas, M., and Burrows, J.: Stratospheric aerosol extinction coefficient, available at: http://www. iup.uni-bremen.de/scia-arc/, last access: 31 May 2018b.

McLinden, C. A., Bourassa, A. E., Brohede, S., Cooper, M., Degenstein, D. A., Evans, W. J. F., Gattinger, R. L., Haley, C. S., Llewellyn, E. J., Lloyd, N. D., Loewen, P., Martin, R. V., McConnell, J. C., McDade, I. C., Murtagh, D., Rieger, L., von Savigny, C., Sheese, P. E., Sioris, C. E., Solheim, B., and Strong, K.: OSIRIS: a decade of scattered light, B. Am. Meteorol. Soc., 93, 1845-1863, 2012.

Palmer, K. F. and Williams, D.: Optical constants of sulfuric acid; application to the clouds of Venus?, Appl. Optics, 14, 208-219, 1975.

Rault, D. F. and Loughman, R. P.: The OMPS Limb Profiler environmental data record algorithm theoretical basis document and expected performance, IEEE T. Geosci. Remote, 51, 2505-2527, 2013.

Rieger, L. A., Bourassa, A. E., and Degenstein, D. A.: Stratospheric aerosol particle size information in Odin-OSIRIS limb scatter spectra, Atmos. Meas. Tech., 7, 507-522, https://doi.org/10.5194/amt-7-507-2014, 2014.

Rieger, L., Bourassa, A., and Degenstein, D.: Merging the OSIRIS and SAGE II stratospheric aerosol records, J. Geophys. Res.Atmos., 120, 8890-8904, 2015.

Rodgers, C. D.: Inverse Methods for Atmospheric Sounding: Theory and Practice, vol. 2, World Scientific, 2000.

Rozanov, V., Rozanov, A., Kokhanovsky, A., and Burrows, J.: Radiative transfer through terrestrial atmosphere and ocean: software package SCIATRAN, J. Quant. Spectrosc. Ra., 133, 13-71, 2014.

Rozanov, A., Rozanov, V., and Burrows, J. P.: SCIATRAN radiative transfer model and retrieval software, University of Bremen, available at: http://www.iup.uni-bremen.de/sciatran/, last access: 30 May 2018.

Thomason, L. W., Ernest, N., Millán, L., Rieger, L., Bourassa, A., Vernier, J.-P., Manney, G., Luo, B., Arfeuille, F., and Peter, T.: A global space-based stratospheric aerosol climatology: 1979-2016, Earth Syst. Sci. Data, 10, 469-492, https://doi.org/10.5194/essd-10-469-2018, 2018.

von Savigny, C., Ernst, F., Rozanov, A., Hommel, R., Eichmann, K.U., Rozanov, V., Burrows, J. P., and Thomason, L. W.: Improved stratospheric aerosol extinction profiles from SCIAMACHY: validation and sample results, Atmos. Meas. Tech., 8, 5223-5235, https://doi.org/10.5194/amt-8-5223-2015, 2015.

Zawada, D. J., Bourassa, A. E., Lloyd, N. D., Roth, C. Z., and Degenstein, D. A.: SASKTRAN, available at: https://arg.usask.ca/ docs/sasktran/, last access: 30 May 2018.

Zawada, D. J., Dueck, S. R., Rieger, L. A., Bourassa, A. E., Lloyd, N. D., and Degenstein, D. A.: High-resolution and Monte Carlo additions to the SASKTRAN radiative transfer model, Atmos. Meas. Tech., 8, 2609-2623, https://doi.org/10.5194/amt-82609-2015, 2015. 